\title{
La IAP como alternativa metodológica para el cambio social: un análisis desde distintas perspectivas
}

\section{The participatory action research as a methodological alternative for social change: analysis from different perspectives}

\author{
Adriana Consuegra-Ascanio $^{1} \&$ Karen Mercado-Villarreal $^{2}$
}

\begin{abstract}
Resumen
El quehacer de las ciencias sociales ha propuesto distintos enfoques y diseños metodológicos para abordar la complejidad de la realidad social y generar transformaciones importantes en la misma. En este contexto, ha imperado el modelo neoliberal desde el que se proponen directrices específicas para encauzar las acciones individuales y colectivas al fortalecimiento del statu quo y legitimación de las prácticas dominantes. A tenor de lo anterior, el presente trabajo propone en primer lugar, abordar aspectos claves de la Investigación-Acción Participativa como alternativa metodológica para promover el cambio social a partir de cuatro perspectivas fundamentales: La IAP como alternativa viable para la descolonización del conocimiento propio de las ciencias sociales. La IAP como postura crítica con respecto al modelo político-económico hegemónico. La IAP como marco pedagógico para la construcción de un modelo educativo e investigativo emancipatorio, y por último la IAP como apuesta política para el cambio social en Colombia, donde se resalta el papel de los movimientos sociales en la consecución de transformaciones estructurales y la pertinencia de la IAP como una metodología capaz de abarcar la acción y la reflexión sobre las múltiples realidades sociales y su constante transformación.
\end{abstract}

Palabras Clave: IAP; cambio social; decolonialidad; modelo económico neoliberal; globalización

\begin{abstract}
Social sciences have conceived several methods, approaches and methodological tools to tackle the complexity of social reality and get to transform it in depth. Yet, the dominant view has followed a neoliberal model that merely proposes specific guidelines aimed at promoting both individual and collective actions that strengthen status quo and keep dominant practices in place. On the contrary, this article highlights four key aspects of Participatory Action Research (PAR), that make it a methodological alternative to promote social changes. First: PAR as a way to decolonize proper knowledge in social sciences and through them. Second: PAR as a critical stance towards the
\end{abstract}

Tipología: Artículo de reflexión

Recibido: $30 / 03 / 2016$

Evaluado: 06/10/2016

Aceptado: 13/10/2016

Disponible en línea: 01/03/2017

Como citar este artículo: Consuegra-Ascanio, A. \& Mercado-Villarreal, K. (2017). La IAP como alternativa metodológica para el cambio social: un análisis desde distintas perspectivas. Jangwa Pana, 16 (1), 90 - 102. Doi: http://dx.doi.org/10.21676/16574923.1959

1. Abogada. Miembro del semillero de investigación Enclave. Universidad del Atlántico. Colombia. Correo electrónico: adriana.consuegra30@gmail. com. ORCID ID: 0000-0002-8300-3375

2. Socióloga. Miembro del Semillero de Investigación Enclave. Universidad del Atlántico. Colombia. Correo electrónico: karen.mercadovillarreal@ gmail.com. ORCID ID: 0000-0002-2223-8103 
hegemonic economic and political model. Third, PAR as a pedagogical frame to think of research and education as emancipatory actions, and finally, PAR as a political option for social change in Colombia. It is highlighted the role of social movements in getting structural transformations. Also, the relevance of PAR as a methodology combining action and reflection on many-faceted and ever-changing social realities is addressed.

Keywords: PAR; social changes; emancipatory education; decolonization; neoliberalism; globalization

\section{Introducción}

$\mathrm{L}$ os primeros soportes teóricos y metodológicos que fundamentaron la IAP en contraposición a los aportes positivistas, estuvieron a cargo de Kurt Lewis (1946-1952) quien le otorgó una entidad propia al acto de investigar al intentar establecer una forma de investigación que no se limitara a la producción de material bibliográfico, sino que articulara la experimentación científica con la intervención social (Garrido, 2007). En este sentido, surge en la década del setenta en Gran Bretaña en un contexto más relacionado con la educación una reflexión de la IAP como una metodología para transformar la realidad social y la práctica educativa a partir de las pesquizas que los mismos docentes realicen sobre su quehacer. De acuerdo con Stenhouse (1990) (citado en Garrido, 2007)

IAP no es simplemente una técnica de investigación para ocasionar cambios en la educación, sino que las ideas educativas sólo expresan su auténtico valor cuando se intenta traducirlas a la práctica, algo que sólo pueden hacer los «enseñantes» investigando con su práctica y con las ideas con las que intentan guiarse. (p.112)

En Latinoamérica por el mismo período, fue propuesto por Fals Borda un enfoque de la IAP con un carácter crítico, emancipatorio e integrador cuyo objetivo principal fue empoderar y darle voz a los actores sociales. El citado autor la definió como "una vivencia necesaria para progresar en democracia; como un complejo de actitudes y valores, y como un método de trabajo que da sentido a la praxis en el terreno." (Fals
Borda, 1999, p. 9). De esta forma, las ciencias sociales se desprenden de su superioridad y se ponen al servicio de las comunidades para lograr una simbiosis entre conocimiento científico y saber popular y ancestral, con el fin de tener un acercamiento más complejo a las problemáticas sociales encauzado a la promoción de acciones concretas para transformar las realidades. La Investigación-Acción Participativa supone una constante reflexión crítica sobre los fenómenos sociales, en la que no solo figura el científico social, sino que todos los miembros de las comunidades que participan en los procesos son considerados como investigadores $\mathrm{y}$ actores fundamentales en la toma de decisiones y en la proposición de alternativas de cambio. En consecuencia, sucede un distanciamiento con las posturas defensoras de la investigación tradicional en la que según Díez (2013)

El investigador se mantenía alejado de los fenómenos, escudado en una actitud de no ingerencia y de no intervención que asegurasen la supuesta posibilidad de una objetividad "pura". Supera así la dicotomía sujeto-objeto en el proceso de investigación, haciendo recaer el peso de la objetividad en la experiencia compartida, por lo cual, el objeto es fruto de la intersubjetividad social (p. 122).

Ahora bien, es importante reflexionar de qué manera la Investigación-Acción Participativa se configura como un enfoque para promover el cambio social a partir de la construcción de un saber endógeno y de la formación de una postura crítica con relación a la hegemonía del sistema capitalista, así como de los modelos de investigación positivistas; defendiendo 
la relación entre teoría y praxis, saber científico y saber popular, lo cual se traduce en la superación de la tensión sujeto-objeto al considerar a los miembros de las comunidades de base como sujetos de la investigación y no como objetos de estudio.

La primera perspectiva presenta a la IAP como una alternativa para la superación del eurocentrismo, ya que se le reconoce a Europa como la génesis de la formulación de conocimiento valido $\mathrm{y}$ científicamente aceptado; como una tradición, pero además, en una vía alterna se consideran de gran impacto y contundencia los aportes que se han hecho desde y para América Latina y el Caribe, todos surgidos a través de la observación y análisis de realidades inmediatas y contextos específicos.

Para el logro de este objetivo se tomaran aportes metodológicos y epistemológicos de la teoría decolonial en general y las posturas desde el sur, entendiendo "el sur" no como una locación exclusivamente geográfica, sino como una corriente epistemológica, que es el

\section{(...) reclamo de nuevos procesos de producción, de valorización de conocimientos válidos, científicos y no científicos, y de nuevas relaciones entre diferentes tipos de conocimiento, a partir de las prácticas de las clases y grupos sociales que han sufrido, de manera sistemática, destrucción, opresión y discriminación causadas por el capitalismo, el colonialismo. (De Soussa, 2009, p.16).}

En un primer momento, se abrirá la discusión con la postura de Quijano y la visión algo desoladora de Roitman (2008) en cuanto a los efectos colaterales negativos que la colonización y la modernización, impuesta a Sudamérica por Europa, junto con la globalización y el arraigo al sistema económico predominante que proviene de Norteamérica, han dejado como saldo en América Latina. En contraste con los aportes de López Segrera (2005) en donde se reivindica la emergencia de conocimiento propio desde y para América Latina. Discusión que continuará con los aportes de Walsh (2009) y su análisis colonialidad del ser y del saber y Quijano (2000) con la colonialidad del poder y sus efectos en la cara "positiva" y la cara oculta. Por último, se integra a la discusión la emergencia de la Investigación-Acción Participativa como una alternativa metodológica y se rescatan sus inicios en Colombia a finales de 1970, a partir de los trabajos adelantados por Fals Borda y un grupo de intelectuales. Según lo anterior se reconoce que, si bien existe un gran acerbo teórico y científico proveniente de Europa y Norteamérica los científicos de la Zona Sur (en clave Falsbordiana) están llamados a trazar nuevas rutas basadas en la producción de un saber propio alimentado de las realidades latentes y manifiestas de América Latina y el Caribe.

La segunda perspectiva reconoce a la IAP como postura crítica que evoca formas alternas reivindicadoras y sostenibles de realizar transformaciones estructurales en las diversas y convulsionadas realidades latinoamericanas y caribeñas. Es así como se parte de los aportes de Max-Neef (1993), con el fin de enunciar que la crisis de esta zona Sur y caribeña no solo se debe a factores de tipo político, económico y social, sino que por el contrario existe una pérdida de la capacidad de "soñar" que debe recuperarse para poder imaginar posibilidades nuevas y diferentes en la búsqueda y desarrollo de los cambios realmente necesarios. Esta visión se complementa con los aportes de Fals Borda (1999) y su justificación a la emergencia de la IAP. A la pertinencia y también a su importancia en la actualidad como alternativa para dar voz a los actores inmersos en los distintos conflictos y múltiples realidades.

Finalmente se articulan los aportes de los autores Robinson y Acemoglu (2012), con relación al papel de las instituciones en economías utilitaristas y clientelistas, que en el caso de Colombia son llamadas instituciones extractivas. En este sentido el interés del presente apartado será proponer a la IAP como una metodología diferente para desarrollar mecanismos de resistencia basados en la inclusión de los sujetos. Para así darles voz en la construcción de una identidad propia que defienda lo diverso y lo autóctono frente a las lógicas homogeneizantes de la globalización. 
La tercera perspectiva integra a la investigación, la educación y la acción como principios fundamentales para la formulación de alternativas que apunten a la formación de sujetos empoderados, activos e interesados en generar transformaciones sociales. A tenor de lo anterior el presente acápite se construye a través de los aportes de Fals Borda (1999) y Freire (2002) de donde toman los referentes para establecer los principios, pedagógicos epistemológicos y metodológicos de la IAP e identificar el fuerte arraigo que ésta tiene en la educación-acción para empoderar a los sujetos como protagonistas de sus realidades concretas, considerándoles como poseedores de conocimientos y no como sujetos pasivos receptores de los mismos.

Por último, la cuarta perspectiva destaca el impacto de la Investigación-Acción Participativa en el rol de los movimientos sociales y las acciones políticas de los sujetos en la búsqueda de modelos sociales integradores e incluyentes en resistencia frente a la hegemonía de las élites económicas, sociales y políticas. Esto se estructurará a partir de una revisión histórica del grupo La Rosca y a su incidencia en distintas comunidades del país (campesinas, obreras, indígenas). Grupo que en la actualidad representan pilares fundamentales para la historia de los movimientos sociales en Colombia.

\section{Discusión}

\section{La IAP como alternativa para la descolonización del conocimiento propio de las ciencias sociales}

Para efectos del desarrollo del presente análisis es necesario identificar el contexto histórico específico dentro del cual empieza a fortalecerse la propuesta de la IAP, a partir de la configuración de principios propios que se van consolidando a medida que el papel del científico social toma rigor y más importancia para el cambio social. En este sentido, Fals Borda (1999) argumenta que en 1970 se presentó un punto de inflexión que motivó girar la mirada hacia los problemas locales (y a la manera en cómo estos estaban siendo abordados). La causa principal fue la rápida puesta en marcha del proceso globalizante y avasallador mediado por los postulados capitalistas, que estaba acabando con la riqueza cultural y biofísica de las diversificadas comunidades indígenas y campesinas principalmente. Fue así como se empezaron "a crear instituciones y formalizar procedimientos alternos de investigación y acción, enfocados hacia los problemas regionales y locales en los que se requerían procesos políticos, educativos y culturales emancipativos" (Fals Borda, 1999, p. 2). Así pues, la IAP se erige como una propuesta metodológica que transforma en gran medida el pensamiento científico social, en contraposición al modelo económico imperante, con la preocupación de darle validez a las culturas propias de cada sociedad; a la luz de principios fundamentales como el reconocimiento de la realidad como totalidad y de la realidad concreta de las diferentes comunidades.

En consecuencia, en América Latina se pueden evidenciar dos efectos: el primero al que haremos referencia tomando los aportes de Quijano es la constitución de América como el primer espacio/ tiempo de un nuevo patrón de poder de vocación mundial y como la primera identidad de la modernidad (Quijano 2000). El segundo efecto alude a la influencia del eurocentrismo en la consolidación e institucionalización de las ciencias sociales en Latinoamérica, lo que ha dificultado de alguna manera la producción de enfoques teóricos desde América Latina y para América Latina. En este sentido, Roitman (2008) muestra como "la sociología en América Latina se comprende como una "recepción" del cuadro de mando que ubica la historia en una dirección que hay que venerar y desde la cual ofrecer una respuesta adecuada" (p.18). Sin embargo, existen otras perspectivas emergentes, como la de López Segrera (2005) que reivindican los procesos de producción de teorías de alcance medio y de axiomas epistemológicos a partir de los cuales se puede dar cuenta de las dinámicas propias de los pueblos latinoamericanos y caribeños. Por ejemplo, el axioma de capitalismo colonial de Sergio Bagú, el axioma centro-periferia 
de Prebisch; el subimperialismo de Ruy Mauro Marini, y el axioma de la dependencia de Theotonio Dosantos. De igual manera, López Segrera (2005) reconoce a la Investigación Acción Participativa, enriquecida por las propuestas de Orlando Fals Borda, como uno de los aportes fundamentales de las ciencias sociales en América Latina y el Caribe.

La IAP como alternativa para la descolonización del conocimiento propio de las ciencias sociales se alimenta con los aportes de Walsh (2009) cuando plantea la necesidad de separarse de los paradigmas hegemónicos como lo son el eurocentrista $\mathrm{y}$ el norteamericano, poniendo de relieve que la modernidad como proyecto históricamente colonizador, en palabras de Mignolo (2010), plantea dos caras, una positiva representada por las ideas de "progreso y desarrollo" y una cara oculta, evidenciada en la colonialidad, en términos de dependencia y sumisión. Ahora bien, para el caso de Walsh (2009) esto se traduce en una reproducción de la idea de modernidad bajo las mismas lógicas de dominación. Así pues, la IAP le apuesta al giro decolonial propuesto desde los enfoques socio críticos al tener como punto de partida el reconocimiento de múltiples formas de poder hegemónico (político, económico, cultural) y de la importancia de contar con las voces y "la experiencia vivida de los sujetos que más han estado marcados por el proyecto de muerte $\mathrm{y}$ deshumanización modernos ya que son altamente relevantes para entender las formas modernas de poder y para proveer alternativas a las mismas." (Maldonado, 2008, p. 66)

Lo anterior se encuentra estrechamente relacionado con la jerarquización racial impuesta por el patrón mundial de colonización introducido en América al que se refiere Quijano (2000) cuando propone la Raza como una categoría mental de la modernidad, en la que se supone que existe una estructura fenotípica y biológica diferente que ubica a los negros, indígenas y mestizos en una situación natural inferioridad respecto de los blancos o europeos. Así pues, se configuran dos formas distintas de colonialidad: la colonialidad del ser que se refiere a la no-existencia y la deshumanización. Una negación del status de ser humano que se inició dentro de los sistemas de complicidad del colonialismo y la esclavitud con el tratamiento de los negros, no como gente sino como cosas del mercado (Walsh, 2009). Y la colonialidad del saber que implica la negación de formas de producción del conocimiento que no sean blancas, europeas y científicas en el sentido cartesiano y newtoniano, lo cual conlleva no solo a elevar la perspectiva eurocéntrica como única línea de pensamiento valida, sino también la autoridad que esta hegemonía posee para determinar qué es conocimiento, cómo se da el conocimiento y quiénes están en capacidades de producirlo y quiénes no. (Walsh, 2009).

Desde este punto de vista, se desecha el valor del conocimiento intelectual y ancestral, para el caso de Walsh o saber popular para Fals Borda, ya que como conocimiento no eurocéntrico no estaría "aportando" al paradigma imperante, por lo cual se deslegitima todo saber que se encuentre por fuera del sistema y sus demandas, restándole importancia a lo que Walsh (2012) llama legado intelectual, basado en el conocimiento tradicional o ancestral de los sectores populares o de los grupos étnicos.

A tenor de lo planteado, es deber de las ciencias sociales en América Latina superar la tradición teórica y epistemológica impuesta desde Europa y Norteamérica para continuar fortaleciendo el pensamiento sociológico latinoamericano, lo que hasta nuestros días aún se presenta como un importante desafío. Es así, que para 1970, según lo declarado por Fals Borda y gracias a una coyuntura vivida a nivel continental y mundial, llega un momento crucial para el desarrollo de lo que sería la IAP: "Entendíamos que las crisis se producían por la expansión del capitalismo y por la modernización globalizante, fenómenos que estaban acabando con la textura cultural y biofísica de las ricas y diversificadas comunidades que conocíamos.” (Fals Borda, 1999, p. 1)

Cabe resaltar que el conocimiento producido a partir de la investigación social se dará desde y para los sectores populares en conjunto con la reciprocidad y dialogicidad que debe existir entre el saber popular y el saber científico para la construcción 
de un conocimiento que trascienda los estándares impuestos. De tal manera que lleve a cabo el proceso investigativo (investigar, enseñar y publicar), las "reglas del juego" que Stavenhagen (1971) sugiere deben ser modificadas, en vez del rol del investigador. Finalmente agrega que el problema de la parcialidad con el que se asume el conocimiento impartido del investigador "depende de dos factores importantes: El primero, la naturaleza y calidad de la investigación, el segundo la difusión a usuarios potenciales.” (Stavenhagen 1971, p. 40) He aquí uno de los antecedentes principales a partir de los cuales se desarrollaron las técnicas de "imputación acumulativa de información" y su "devolución sistemática", implementadas por Fals Borda en sus investigaciones. (Fals Borda 1999, p. 81)

\section{La IAP como postura crítica con respecto al modelo económico imperante: prácticas dominantes y lógica homogeneízante}

La caracterización de la IAP como un proceso de investigación invita a la participación de los actores desde su inicio, demostrando que lo importante es levantar las voces de quienes han permanecido callados por la opresión de las instituciones excluyentes y darle vida a una serie de ideas que van planteando soluciones desde el autoreconocimiento de las comunidades en sí mismas y de sus problemáticas. Este es el principal motivo por el cual la IAP se erige como una filosofía de vida que se traduce en una posición crítica frente a los parámetros ya establecidos y busca transformaciones estructurales y concretas que posibiliten la construcción de modelos económicos, políticos o sociales basados en la justicia y coherentes con la realidad concreta de los sujetos.

Si bien es cierto que de alguna manera una visión como esta resulta bastante ambiciosa, no se puede negar que desde pequeños cambios se va transformando el mundo. Tal como lo mencionaría Max Neef (1993) en su obra Desarrollo a escala humana, la crisis que atraviesan los países de América Latina, no se debe únicamente a problemas sociales, económicos o políticos, la peor crisis que enfrenta América Latina es la crisis de utopía, precisamente porque lo que se está perdiendo es la capacidad de soñar. Desde el mismo momento en que la planificación de proyectos para el desarrollo de las comunidades se realiza partiendo del conocimiento que tienen las personas sobre su realidad concreta, se van gestando modificaciones al statu quo y se trabaja por la materialización de condiciones de vida acordes con las necesidades de los sujetos. A través de la concientización y del empoderamiento de los pueblos, se empieza a forjar el camino para la emancipación y para la autonomía de los sectores populares en la toma de decisiones.

La introducción de un modelo económico capitalista neoliberal que consiste en una menor intervención del Estado en las acciones económicas de las personas o en el funcionamiento de instituciones sociales y culturales, ha traído como resultado la marginación de ciertos sectores poblaciones y la implementación de políticas económicas contrarias a las particularidades históricas y sociales de los pueblos.

A principios del noventa se dio la apertura económica que favoreció la adaptación del modelo económico neoliberal en Colombia, la cual ha traído serias consecuencias a nivel económico y cultural en el país, como la configuración de instituciones económicas y políticas extractivas que como lo exponen Robinson \& Acemoglu (2012) se caracterizan por estar diseñadas bajo una concepción clientelista y utilitarista, a fin de satisfacer intereses individuales y no intereses colectivos. Ante esto es importante que el investigador social tome posturas críticas que lo lleven a replantearse su función en la sociedad y que lo animen a crear y recrear alternativas de solución en las que se reconozca como punto de partida la voz de los marginados u oprimidos por el sistema neoliberal, para la creación de políticas eficaces y entornos viables con el objetivo de lograr un modelo de desarrollo que abarque todas las dimensiones del individuo y de la sociedad.

Insistiremos que la cultura y la economía no son las únicas áreas que han sido tocadas por las lógicas 
impositivas del neoliberalismo. Actualmente, el sistema educativo también responde a las dinámicas del mercado, formando seres competitivos y funcionales para el sistema social universalizado que se ha construido a partir de la acumulación del capital y crecimiento económico. La formación en ciencias sociales no escapa a esta realidad y por esto, como lo plantean Lourenco, Roig y Sanz (2008), la relación directa que hoy existe entre universidad y mercado influye en las líneas $\mathrm{y}$ procesos de investigación que se gestan en las universidades y que en un gran número de casos obliga a los profesionales a legitimar parámetros propios del sistema.

Un enfoque funcional-estructuralista llevaría a entender este tipo de situaciones, si se tiene en cuenta que la sociedad (desde estas teorías) es un sistema compuesto por varios subsistemas, autónomos e independientes pero que se articulan para un perfecto funcionamiento de ese gran sistema social. En este sentido, los individuos no son más que elementos funcionales que colaboran para lograr que el sistema "funcione" en perfecto orden (Mills, 1969). Lo anterior solo se logra a través de las instituciones normativas o culturales que constituyen un esquema de creencias y expectativas que le dan estatus legítimo a las acciones impuestas desde las altas esferas sociales.

En contraposición a esto, se propone desde los lineamientos epistemológicos de esta alternativa de investigación (IAP) que se observe la realidad como un todo y que se tome como punto inicial la realidad concreta de los individuos (Gabarrón \& Hernández, 1994). Ello implica que la realidad social sea vista de manera holística y no fragmentada, como lo establecen los enfoques positivistas o funcionalestructuralistas, que únicamente analizan lo que es susceptible de medición. Además, se busca asumir a los sujetos como principales conocedores de su propia realidad, admitiendo que esta no es un conjunto de simples categorías objetivas sino que también está compuesta de las representaciones subjetivas que los individuos tienen de ella. Así pues, se le otorga al investigador social una serie de herramientas para adoptar una posición crítica que lo conduzca al reconocimiento del saber popular como elemento clave para la emancipación de los sectores oprimidos y para la ejecución de prácticas transformadoras provenientes de una relación dialógica (Lourenco, et al, 2008).

Con relación al quehacer del científico social y para el caso específico del proceso de institucionalización del pensamiento sociológico latinoamericano han existido posturas las cuales han contribuido a la complejidad del análisis de las dinámicas propias de la región, tal es el caso de la teoría de centro periferia propuesta y elaborada por Raúl Presbisch, resaltada a su vez por López Segrera (2005) como el tercer axioma en la tradición del pensamiento social latinoamericano. Este axioma tiene sus implicaciones metodológicas al considerar que la dinámica de los países en vías de desarrollo no puede analizarse independientemente de su posición dentro de la economía mundial. Sus procesos de desarrollo son cualitativamente diferentes a los de las naciones más avanzadas. Esto implica, en particular, que no hay "etapas de desarrollo" uniformes, que el "capitalismo periférico" tiene una dinámica diferente al de las naciones que experimentaron un desarrollo más temprano y se transformaron en el "centro" de la economía mundial. (Ocampo, 2001)

\section{Investigación, educación y acción: las bases de la Investigación-Acción Participativa}

Plantear la IAP como alternativa para el cambio social, aun cuando sus principios tanto metodológicos como epistemológicos se nutren en una discusión vigente, se constituye en un reto bastante ambicioso. Empero, la IAP ha demostrado a través de experiencias y rigurosas investigaciones, que como herramienta sus aportes resultan bastante útiles para los procesos emancipatorios que deben llevarse a cabo en nuestras comunidades oprimidas. En palabras de Fals Borda (1999) investigación, acción y enseñanza políticamente comprometidas se destacan como solución ante la discriminación y la dominación de la que son víctimas los sectores 
populares o vulnerables de la sociedad. Teniendo en cuenta que la IAP implica la democratización, la consolidación de una democracia participativa desde abajo hacia arriba con movimientos sociales, políticos y culturales de apoyo. Importante es resaltar que esta alternativa metodológica desde sus inicios se ha propuesto superar una serie de obstáculos para llevar a cabo su propósito: discusión ciencia, conocimiento y razón sobre la teoría y la práctica y la tensión existente entre sujeto y objeto.

Con respecto a la discusión sobre la ciencia, conocimiento y razón, el citado autor argumenta que "Para empezar a dirimir estas cuestiones, pusimos en entredicho la idea fetichista de ciencia-verdad que nos había sido transmitida como un complejo lineal y acumulativo de reglas confirmadas y leyes absolutas." (Fals Borda, 1999 p. 75) Conforme a ello se empieza a notar que la ciencia también se construye socialmente y que por tal razón esta se somete a interpretación, reinterpretación, revisión y reconocimiento (Fals Borda, 1999, p. 5). Existía una falencia por parte del conocimiento científico para explicar la realidad social, ya que no se daba una verdadera interacción con el "objeto" de estudio y el investigador como "sujeto". Al descubrir que podían darse convergencias entre el pensamiento popular y la ciencia académica, se avanza en ganancia porque se empieza a construir un conocimiento mucho más completo de la realidad, en especial para aquellas clases desprotegidas las cuales tienen necesidades de apoyo científico para llevar a cabo sus objetivos.

El papel de la educación en este aspecto es fundamental porque desde esta visión se propone una discusión en contra de las grandes teorías impuestas y reproducidas por el estructuralismo, ya que pone en igualdad de condiciones el saber popular y el saber científico, como polos que deben converger en una simbiosis que logre aportar rigor a la investigación y la acción social; pero que a su vez no deje de lado la participación de los miembros de la comunidad como un aporte complementario y absolutamente necesario para la reconstrucción de este discurso reivindicativo que se ha venido mencionado.
Sobre la teoría y la práctica, se tomó como principio elcompromiso-acción en remplazo del compromisopacto, adoptado de la tradición académica, debido a que existían una serie de preocupaciones con respecto al enfoque según el cual se pretendía mirar la investigación, ya que se observaba que con el pasar del tiempo algunos investigadores voluntaria e involuntariamente terminaban apoyando el statu quo con lo que nublaban la realidad (Fals Borda, 2008). La descolonización del pensamiento, implica ahondar y descubrir en las mentes propias todas aquellas conductas reaccionarias que se consideren impuestas gracias al proyecto educativo. El compromiso-acción está inspirado en la praxis y en el poder que posee la intervención social, a través de la inserción del investigador en la realidad para llegar a procesos concretos de la acción social.

Para lograr la superación de la tensión sujetoobjeto, como principio fundamental de la IAP, tal y como es enunciado por Fals Borda (1999), se hacía necesario "impedir la mercantilización o cosificación de los fenómenos humanos que ocurre en la experiencia investigativa tradicional y en las políticas desarrollistas." (p. 78) Por lo tanto,

Parecía contra-productivo considerar al
investigador y al investigado o al "experto"
y los "clientes", como dos polos antagónicos,
discordantes o discretos. En cambio, quería
verlos a ambos como seres "sentipensantes",
cuyos diversos puntos de vista sobre la
vida en común debían tomarse en cuenta
conjuntamente (Fals Borda, 1999, p. 78).

Ahora bien, desde este mismo enfoque se encuentra el planteamiento freiriano con la crítica realizada a la visión bancaria de la educación, la cual se caracteriza por anular "el poder creador de los educandos estimulando así su ingenuidad y no su criticidad" (Freire, 2002, p. 7) satisfaciendo de esta forma el interés de los opresores y reproduciendo las lógicas del modelo neoliberal ya que su pretensión (la de los opresores) es transformar la mentalidad de los oprimidos y no la situación que los oprime con el fin de lograr una mejor adaptación a la situación que a la vez permita una mejor forma de dominación. (Freire, 2002) 
Por último, este autor brasilero agrega que es necesario considerar a los sujetos no como receptores pasivos de los conocimientos transferidos por los educadores sino como sujetos activos poseedores de conocimientos y experiencias, poniendo de relieve la necesidad de propiciar una relación dialógica en la que ambas partes sean constructoras del conocimiento de manera simultánea (Freire 2002). Por consiguiente, según Fals Borda (citado en Gabarrón \& Hernández, 1994) la investigación, acción y educación se convierten en momentos metodológicos de un solo proceso para la transformación social, teniendo en cuenta que la IAP

Es más que un procedimiento investigativo y una técnica de investigación de adultos y una acción política, fases todas ellas que se pueden combinar en una metodología dentro de un proceso vivencial, es un procedimiento de conducta personal y colectiva que se desenvuelve durante un ciclo productivo satisfactorio de vida y de trabajo. Es una forma especial de combinar conocimiento y poder cuya mira es la edificación de un poder o contrapoder, que pertenezca a las clases y grupos pobres, oprimidos, explotados; y a sus organizaciones auténticas (p.143).

\section{La IAP como apuesta política para el cambio social en Colombia}

\section{La IAP y el papel político de los movimientos sociales.}

Se han mostrado piezas de un análisis teórico que busca construir un discurso en el que se resalte que finalmente la IAP es una apuesta política para el cambio social, en la que se reivindica el poder "concienzador" y transformador de los movimientos sociales, organizaciones de bases comunitarias, líderes y lideresas. Pues bien, el rompimiento de la tensión sujeto-objeto planteado desde la IAP como condición sine qua non para la consecución de transformaciones concretas en la sociedad, explica el reconocimiento del papel político de los movimientos sociales y del investigador social con la comunidad como base fundamental para trascender del plano meramente teórico a la combinación praxis-teoría, en el que se ponga la política y la ciencia al servicio de la comunidad para la superación de modelos de planificación impositivos y excluyentes.

Teniendo en cuenta la pluralidad de aportes con respecto a la relación existente entre IAP y movimientos sociales, se propone específicamente para tratar este acápite los análisis de Orlando Fals Borda contenidos en los textos de Cataño (2008): Orlando Fals Borda, sociólogo del compromiso y el texto de Zubiría (2014): El pensamiento de Fals Borda con relación al papel político de los movimientos sociales. En ambos se resaltan las distintas etapas del pensamiento falsbordiano, en donde se identifica un momento crucial en la vida intelectual de este autor, caracterizado por la ruptura de su afinidad con el pensamiento euroamericano y por consiguiente la superación del apego teórico relacionado con el análisis de las realidades de los pueblos latinoamericanos, provocando un interés hacia los enfoques sociocríticos surgidos en América Latina que posteriormente se materializan en la consolidación de la Investigación-Acción Participativa como un "proceso de creación intelectual y práctica endógena de los pueblos del tercer mundo." (Zubiría, 2014, p. 31).

El reconocimiento del papel político de los movimientos sociales al que alude Fals Borda en gran parte de sus obras surge en circunstancias de tiempo y espacio coyunturales en Colombia. Era el periodo convulsionado del Frente Nacional, en el cual los partidos políticos tradicionales se repartieron el poder dejando por fuera a distintos sectores de la sociedad en la lucha democrática y participativa para la toma de decisiones de gran relevancia relacionadas con las condiciones sociales, económicas y políticas del país. En estas circunstancias marcadas por distintas caras del conflicto, Orlando Fals Borda hace una apuesta académica a nueva forma de comprender y transformar la realidad social: la sociología comprometida, que en esencia consiste en dejar de lado la neutralidad y la objetividad al momento de planificar y proponer estrategias para el desarrollo en las comunidades, para enfocarse en el compromiso político que tiene el investigador, de manera que los resultados de la investigación no se 
deben destinar únicamente a multiplicar el acervo de la ciencia o a iluminar la inteligencia de las elites del Estado. Por el contrario, debe retomar a las personas que los han producido. (Cataño, 2008)

Lo anterior sirvió de precedente para el nacimiento de la IAP como estrategia teórica y metodológica en el cual los movimientos sociales ostentan igual relevancia que los partidos políticos, en la medida en que estos construyen una nueva cultura política que supera el sectarismo y crean frentes unidos de acción; trascendiendo de la protesta a la propuesta, (Zubiria, 2014) y conformando canales y redes de intercambio y de potenciación del capital social comunitario.

\section{La Rosca: Un espacio académico-político para el surgimiento y la consolidación de la Investigación-Acción Participativa.}

La IAP como proyecto político tiene su nicho en el seno de La Rosca, debido a que el escenario académico de la época estaba permeado por los cánones científicos que exigían una neutralidad valorativa y proponían ordenamientos curriculares ajenos al acercamiento a las comunidades campesinas e indígenas, por lo cual se requería la conformación de una organización política que le hiciera frente a estas coyunturas partiendo de las organizaciones de base comunitarias. De igual forma se aclara que para comprender la finalidad de la IAP no se debe dejar de lado que esta tuvo dos momentos específicos que se evidenciaron en el proceso de conformación de La Rosca y fueron los siguientes:

El primero de ellos se dio en julio de 1970 en donde se propone una técnica denominada ParticipaciónInserción que suponía la participación comunitaria exclusivamente en términos de recolección de información e insumos para la planificación, dejando de lado la voluntad política y el reconocimiento de las comunidades como sujetos conocedores y transformadores de su realidad.

El segundo momento se caracteriza por un balance crítico a la producción científica frente al proceso investigativo adelantado, lo que produjo que en
1971 se supera la técnica Participación-Inserción para abrirle campo a la Investigación-Acción Participativa en la que se introducen nuevos conceptos tales como la devolución sistemática y la recuperación crítica. A partir de aquí tuvo lugar la creación de obras importantes como el documento: Bases para un movimiento de acción independiente, en el cual se hizo un análisis de la situación coyuntural colombiana a comienzos de 1972, alimentado por los fundamentos teóricos provenientes de los estudios realizados desde la Cepal y de los constructos epistemológicos nacidos de teorías como la teoría de la dependencia y la de centro periferia, lo cual culminó con una invitación a constituir un movimiento político con base en ideales de trabajo, justicia, oportunidad y unión: La Rosca.

Dentro de la producción académica de la Rosca se tiene:

- Plan de acción rural, La Rosca emite un documento de trabajo fechado el 19 de enero de (1971) que señalaba "un vacío político debido a que los campesinos no han logrado articular aun sus nuevas lealtades y actitudes hacia los grupos que surgen y los fenómenos nuevos." Se vio que ese vacío se intentó llenar con movimientos de protesta, como la Alianza Nacional Popular (ANAPO), con el esporádico respaldo a las guerrillas del Ejército de Liberación Nacional (ELN), Ejército Popular de Liberación (EPL) y de las Fuerzas Armadas Revolucionarias de Colombia (FARC) con invasiones aisladas a haciendas, sabotaje a mercados y bloqueo de carreteras. También estaba haciendo sus primeros escarceos la Asociación Nacional de Usuarios Campesinos (ANUC).

- Recopilación de trabajos de Manuel Quintín Name y del pionero socialista y líder sindical de la década de 1920 Ignacio Torres Giraldo con dos obras: En defensa de mi raza y La cuestión indigena en Colombia. Esta recopilación constituyeron un acontecimiento intelectualpolítico de gran envergadura nacional

- PublicacióndelibroPorahíes lacosa,recopilación de conferencias dictadas en Barranquilla, gracias la concentración de sindicatos de maestros. 
- Folleto El petróleo es del pueblo colombiano como resultado del cursillo sindical de Tibú, que brindo las pautas para sucesivas entregas de este tipo de folletos ilustrados políticos como medio para concientizar a las masas semiletradas, especialmente las campesinas.

- Documental Mar y Pueblo, rodado en Buenaventura, comprometido con la lucha popular que estimuló y dio bases para la producción de la Escuela Crítica de Cine Militante en Colombia.

- Revista Alternativa: era una revista que aglutinaba la perspectiva de algunas fuerzas de izquierda y sirvió como laboratorio de nuevas técnicas de comunicación social, para llegar efectivamente con un mensaje de concientización al pueblo colombiano. Su primer número se publicó el 15 de febrero de 1974 y fue dedicado a la contraguerrilla en acción. El primer autor sumado a esta iniciativa fue Gabriel García Márquez, quien brindó aportes formales a la realidad política en Colombia a partir de sus publicaciones en esta revista.

\section{Conclusiones}

Se han planteado a lo largo de este documento distintas perspectivas para contribuir a la discusión actual sobre la IAP como alternativa metodológica para el cambio social. Cada una de las perspectivas encierra una idea fundamental y es el carácter político de la Investigación- Acción Participativa partiendo de su esencia teórica y epistemológica con miras a las transformaciones estructurales de la sociedad.

América Latina como realidad inminente y concreta, se constituye en un amplio campo de estudio, debido a las grandes contradicciones que al interior del continente existen; entre ellas las dinámicas homogeneízantes de la globalización como un constructo teórico desconocedor de la realidad concreta de las diferentes comunidades; la avasalladora dinámica del sistema capitalista como aparato ideológico imperante y las políticas neoliberales que suponen una visón mercantil de la educación (la universidad como empresa), introduciendo a los estudiantes en las dinámicas del mercado global y en la acumulación masiva del capital. Sin embargo, se destaca a la IAP como una alternativa metodológica robustecida por un gran acervo teórico que le permite situarse alrededor de distintas perspectivas, para responder a cuestiones importantes como la participación de los sujetos y movimientos sociales en las transformaciones sociales. En esta medida se retoman los aportes de Freire (2002) cuando afirma que los individuos permanecen
(...) dentro de la estructura que los transforma en "seres para otro". Su solución, pues, no está en el hecho de "integrarse", de "incorporarse" a esta estructura que los oprime, sino transformarla para que puedan convertirse en "seres para sí", es decir en sujetos activos que puedan ser agentes de cambio. (p. 82)

Dentro de este mismo marco, se toman en cuenta dos décadas fundamentales en la realidad del Sur como lo evoca Fals Borda (2008): La década del setenta como punto de partida que supone una ruptura con el paradigma eurocentrista; la ineficacia de las investigaciones realizadas bajo esta línea de pensamiento dio paso a la reformulación y construcción de un pensamiento endógeno capaz de atender a las necesidades propias de la realidad concreta de cada una de las sociedades. Y la década del noventa como momento histórico para el caso colombiano, donde comienzan a implementarse todas las políticas de corte neoliberal que generó profundas crisis y movilizaciones que cambiaron radicalmente el curso mismo de la sociedad. Fals Borda (2008) señala que la capacidad del científico social debe ir enfocada hacia la complementariedad y discusión dialógica entre las grandes teorías y la realidad social propia, para eso el saber popular cobra una gran y absoluta importancia en la construcción de la IAP como metodología para ahondar en la profunda realidad de las comunidades a las que se les ha reducido a la opresión y que a su vez estas han interiorizado.

La capacidad de dar crédito a un "saber" distinto al que ha sido inculcado en edades tempranas, demuestra que es posible empezar a creer en la 
importancia del otro, no como un ente o elemento aislado, sino más bien como un individuo complementario a la sociedad.

Poder ver más allá de lo mostrado superficialmente, es el oficio del investigador social. Un reto que en la actualidad ha tomado fuerza gracias al arraigo y fortalecimiento del discurso dominante. El sociólogo, entonces, debe hacer alusión al "combate" en términos de Bourdieu y situarse a favor de la reivindicación de los oprimidos, la ciencia social crítica debe "desvelar" lo que el stablishment tiene contemplado dentro de un gran sistema como inamovible e invariable.

\section{Referencias bibliográficas}

Acemoglu, D. \& Robinson, J.A. (2012). ¿Por qué fracasan los países? Los orígenes del poder, la prosperidad y la pobreza. Barcelona: Ediciones Deusto.

Castro-Olivas, C. (2005). El modelo neoliberal y la educación. Revista Entre Líneas. Recuperado de: http://revistaentrelineas.blogspot.com/2005/09/elmodelo-neoliberal-y-la-educación.html

Cataño, G. (2008). Orlando Fals Borda, sociólogo del compromiso. Revista de Economía Institucional. 10(19), pp. 79 - 98. Recuperado de http://www.economiainstitucional.com/pdf/No19/gcatano19.pdf

De Soussa, B. (2009). Epistemología del sur. México D.F. : Siglo XXI Editores

Díez, E. (2013). Investigación Acción Participativa: El cambio cultural con la implicación de los participantes. Revista Electrónica Interuniversitaria de Formación del Profesorado. 16(3), pp. 115-131.

Fals Borda, O. (1999). Orígenes Universales y Retos Actuales de la IAP. Revista Análisis Político, 38, pp. 71-78. Recuperado de http://biblioteca.clacso.edu.ar/ ar/libros/colombia/assets/own/analisis38.pdf.

Fals Borda, O. \& Mora-Osejo, L. (2004). La superación del Eurocentrismo. Polis. Revista Latinoamericana, 7, pp. 2-8. Recuperado de http://www.accefyn.org.co/ Lib/docs/Mora.pdf
Freire, P. (2002). Pedagogía del oprimido. Buenos Aires: Siglo XXI Editores Argentina.

Gabarrón, L. \& Hernández L. (1994). Cuadernos Metodológicos. Investigación participativa. Madrid: Centro de Investigaciones Sociológicas.

Garrido, f. (2006). Perspectiva y prácticas de educación-investigación participativa. Revista política y sociedad, 44(1), pp- 107-124. Recuperado de https:// dialnet.unirioja.es/servlet/articulo?codigo $=2306753$

López Segrera, F. (2005). Abrir, impensar, y redimensionar las ciencias sociales en América Latina y el Caribe. ¿Es posible una ciencia social no eurocéntrica en nuestra región? En Lander, E. (Ed.), Perspectivas latino-americanas (pp. 203-226). Buenos Aires: Colección Sur-Sur Clacso.

Lourenco, A., Roig, G. \& Sanz, A. (2008). La investigación acción participativa como herramienta para el sociólogo: De la universidad a la calle. En Romao, A. (Presidencia), VI congresso portugues de sociologia. Mundos Sociais: saberes e prácticas. Asociación Portuguesa de Sociología, Lisboa, Portugal.

Maldonado, N. (2008). La descolonización y el giro des-colonialial. Revista Tabula Rasa, 9, pp. 61-72. Recuperado de http://www.revistatabularasa.org/numero-9/04maldonado.pdf

Max Neef, M. (1993). Desarrollo a escala humana. Barcelona: Icaria Editorial S.A.

Mignolo, W. (2010). La colonialidad: La cara oculta de la modernidad. En W. Mignolo (Ed.), Desobediencia epistémica. Retórica de la modernidad, lógica de la colonialidad y gramática de la descolonialidad (pp. 39-48). Buenos Aires: Ediciones del Signo.

Mills, W. (1969). La imaginación sociológica. México, D.F.: Fondo de Cultura Económica.

Ocampo, L. (2001). Raul Prebisch y la agenda del desarrollo en el siglo XXI. Seminario sobre la Teoría del Desarrollo en los Albores del Siglo XXI: Evento Conmemorativo del Centenario del Nacimiento de don Raúl Prebisch Santiago. Comisión Económica para América Latina y El Caribe, Santiago de Chile. 
Quijano, A. (2000). Colonialidad del poder, eurocentrismo y América Latina. En E. Lander. (Ed.), La colonialidad del saber: eurocentrismo y ciencias sociales. Perspectivas Latinoamericanas. (pp. 246-276). Buenos Aires: Clacso.

Scribano, A. (2012). Teorías sociales del Sur: una mirada post - independentista. Buenos Aires: Estudios Sociológicos Editora.

Roitman, M. (2008). Las maldiciones de pensar América Latina. En M. Roitman. Pensar América Latina. El desarrollo de la sociología latinoamericana. (pp. 15-30). Buenos Aires: CLACSO.
Walsh, C. (2009). Interculturalidad crítica y Educación intercultural. En J. Viaña, C. Walsh \& Tapia, L. Construyendo interculturalidad crítica. (pp. 75-96). La Paz: Instituto Internacional de Integración Andrés Bello.

Walsh, C. (2012). Hacia una comprensión de la interculturalidad. Guadalajara: Tukari.

Zubiría, B. (2014). El pensamiento de Orlando Fals Borda con relación al papel político de los movimientos sociales. Collectivus, Revista de Ciencias Sociales, 1, (1), 28-46. Recuperado de http://investigaciones.uniatlantico. edu.co/revistas/index.php/Collectivus/article/view/1157 